\title{
To Compare the Effect of Muscle Energy Technique and Ultrasound on Jaw Range of Motion in Subjects with Temporomandibular Joint Dysfunction
}

\author{
Dr Jaspinder Kaur, Dr Shilpy Jetly \\ Assistant Professor, DAV Institute of Physiotherapy and Rehabilitation, Jalandhar, Punjab, India
}

\begin{abstract}
How to cite this paper: Dr Jaspinder Kaur | Dr Shilpy Jetly "To Compare the Effect of Muscle Energy Technique and Ultrasound on Jaw Range of Motion in Subjects with Temporomandibular Joint Dysfunction" Published in International Journal of Trend in Scientific Research and Development (ijtsrd), ISSN: 24566470, Volume-3 | Issue-4, June 2019, pp.136-138, URL: https://www.ijtsrd. com/papers/ijtsrd2 3579.pdf

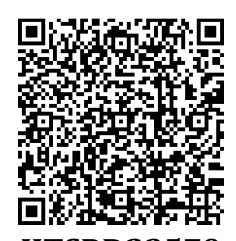

IITSRD23579
\end{abstract}

Copyright (C) 2019 by author(s) and International Journal of Trend in Scientific Research and Development Journal. This is an Open Access article distributed under the terms of the Creative Commons

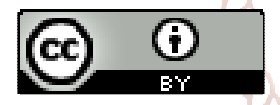
Attribution License (CC BY 4.0) (http://creativecommons.org/licenses/ by/4.0)

\section{INTRODUCTION}

Temporomandibular joint is a horse shaped bone that articulates with the temporomandibular bone. Each temporomandibular joint contains disc that separates the joint into upper and lower articulations. ${ }^{1}$

When TM joint is not working properly, the condition is known as temporomandibular joint dysfunction joint (or disorder). The TMJ are positioned Right in front of ear canals. ${ }^{1}$

Temporomandibular disorder (TMD) refers to the causes responsible for the impaired function of temporomandibular joints (TMJ) and the associated Neuro- musculature system, which may provoke TMD related pain. TMD are a group of dysfunction and disorder related to impaired function of the temporomandibular joints and associated muscles therefore they may lead to the painful impairment in stomatognathic system functioning. The TMJ is used 1500- 2000 times a day, which shows how great discomfort is carried by the pathologies in jaw movements. ${ }^{2}$

The Journal of Headache and Pain Mieszko Wieckiewicz, Klaus Boening, Piotr Wiland, Yuh-Yuan Shiau, Anna
Paradowska-Stolarz Published on Dec 7, 2015 The most commonly reported conservative treatment are massage therapy and individually fabricated occlusal splints. In addition to massage, other methods include mannual therapy (Muscle Energy Technique) and tapping, warming/cooling of aching joint and light and laser therapy. Drugs are also commonly used. In the most severe cases of the temporomandibular joint degeneration, surgical restoration of the joint is some time applied. ${ }^{3}$

Physical Therapy, Marega S Medlicott, Susan R Harris Volume 86, Issue 7, 1 July 2006, Pages 995-973 Published: 1 July 2006 This systemic review analyzed studies examining the effectiveness of various physical therapy and electrotherapy for the temporomandibular joint dysfunction. This study showed result that mannual mobilization and active exercises may be effective in combination with electrotherapy modalites including laser therapy, biofeedback and therapeutic ultrasound. 4

Methodology: This study was experimental and comparative in nature. 
Inclusion Criteria: Individuals having stage 1 temporomandibular joint dysfunction (both unilateral and bilateral), both males and females, cooperative and mentally fit patients were included in the study.

Exclusion Criteria: Patients having caries, braces (which cause limited movement of TM joint), extraction of wisdom tooth causing spasm of facial muscles were excluded from the study.

Protocol: A written consent was obtained from all subjects. Subjects who met the inclusion criteria were included in the study and required assessment of every subject was done. Minimum 20 subjects were allocated in two groups-Group A \& Group B.

In group $\mathrm{A}$, the choice of treatment was:

$>$ Muscle Energy Technique (MET)

In group $B$, the choice of treatment was:

$>$ Ultrasound

Total 5 treatment sessions were given to each group within a week.

\section{Data analysis \& Results}

Data was analyzed using SPSS VERSION 20.0. All the data was measured using descriptive statistics.

COMPARISON BETWEEN THE GROUP A AND GROUP B

Fig. 1 showed comparison of Opening of Mouth between group A and group B. The fig. 1 highlights the (mean \pm standard deviation) $\mathrm{P}$ values between the sessions of Day 1 (pre) was 33.00 \pm 2.449 in group A and $32.00 \pm 1.155$ of group $B$ and Day 5 (post) was $37.20 \pm 4.417$ in group $A$ and $35.60 \pm 2.797$ in group B respectively. The result for this Fig. 1 was non-significant.

Fig. 2 showed comparison of protrusion between group A and group B. The fig. 2 highlights the (mean \pm standard deviation) P values between the sessions of Day 1 (pre) was $5.30 \pm 1.059$ in group A and $6.50 \pm 1.650$ of group B and Day 5 (post) was $7.50 \pm 1.269$ in group $A$ and $8.40 \pm 1.578$ in group $B$ respectively. The result for Fig. 2 was non-significant.

Fig. 3 showed comparison of lateral deviation (right side) between group A and group B. The Fig 3 highlights the (mean \pm standard deviation) $P$ values between the sessions

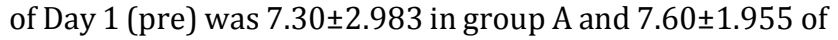
group B and Day 5 (post) was $9.50 \pm 1.581$ in group A and $9.10 \pm 1.101$ in group B respectively. The result for Fig. 3 was non-significant.

Fig. 4 showed comparison of lateral deviation (left side) in between group A and group B. The Fig. 3 highlights the (mean \pm standard deviation) $P$ values between the sessions of Day 1 (pre) was $6.40 \pm 2.319$ in group A and $6.80 \pm 1.033$ of group B and Day 5 (post) was $9.00 \pm 1.886$ in group A and $9.20 \pm 0.789$ in group B respectively. The result for Fig. 3 was non-significant

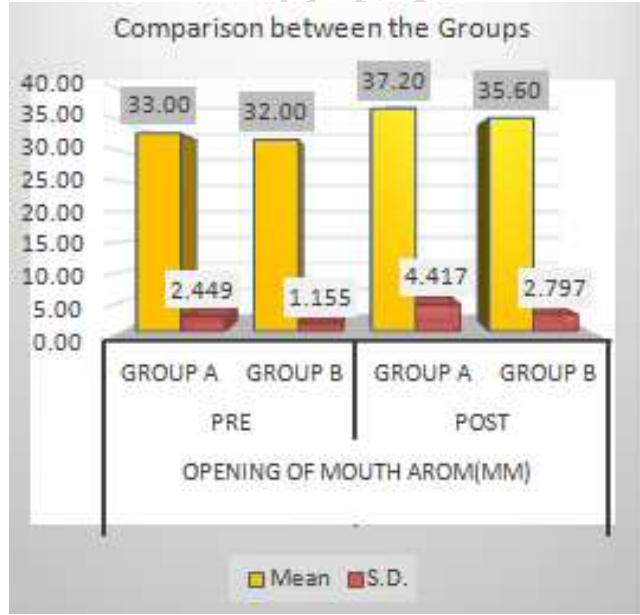

Fig. 1



Fig.3

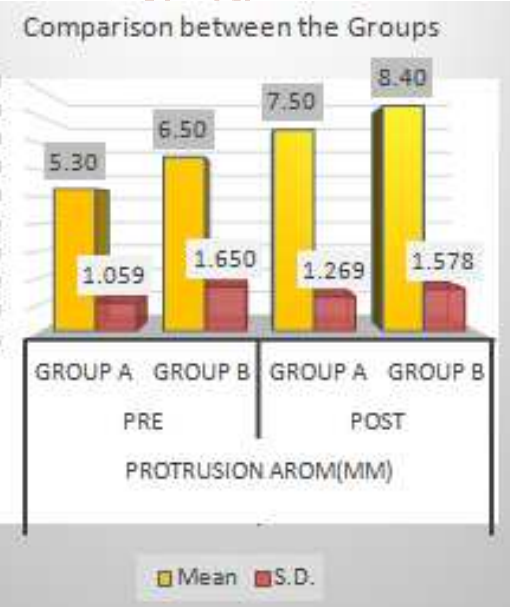

Fig. 2

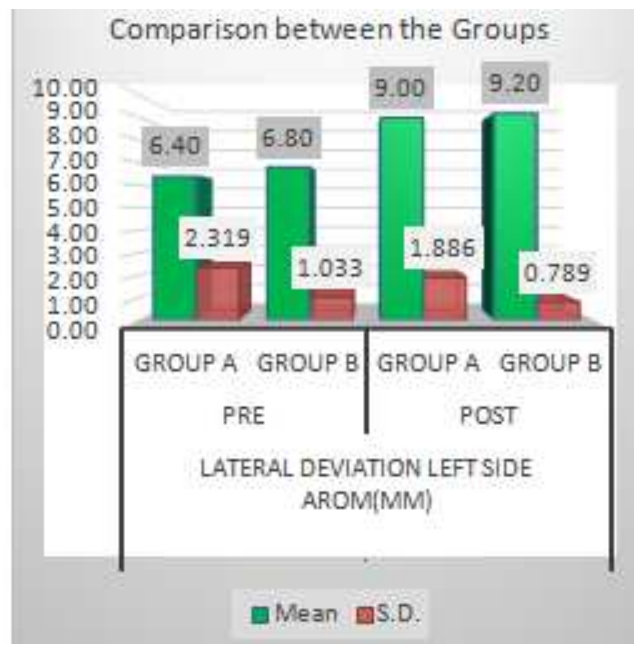

Fig.4 
The aim of the study was to compare the effect of Muscle Energy Technique and Ultrasound on Jaw range of motion in subjects with Temporomandibular Joint Dysfunction.

Both the groups showed significant improvement within the groups. But the study supported $\mathrm{H}_{0}$ hypothesis i.e. nonsignificant difference when compared with each other.

In manipulative therapy the Muscle Energy Technique (MET) is a revolution involving a movement away from high velocity or low velocity amplitude thrusts towards gentle methods which takes far more accounts of soft tissue component. 5

The active contraction of a muscle results in reflexively relaxation of its antagonistic. Opening of mouth against resistance is inclined to relax contracted elevator muscle for opening muscles. ${ }^{6}$

Ultrasound therapy is one of the most widely used deep heating modality in physiotherapy departments. "Ultrasound therapy is electro physical agent based on the application of mechanical energy produced by sound waves of high frequencies between $85 \mathrm{KHz}$ and $3 \mathrm{KHz}$ and delivered at intensities between 0 and $3 \mathrm{~W} / \mathrm{cm}^{2}$ ". Therapeutic frequencies of ultrasound therapy are $1 \mathrm{MHz}$ or $3 \mathrm{MHz} .^{7}$ Ultrasound therapy is one of the efficacious method for reduction of pain, ROM, muscular tonus and improving function of the muscles. ${ }^{8}$

\section{Conclusion}

The study concluded that Muscle Energy Technique (MET) and ultrasound both are effective in temporomandibular joint dysfunction to increase ROM of jaw.

\section{Limitation and future scope of study}

$>$ The sample size for the study was too small.

$>$ Duration of the study was not adequate to study the long term effects of the treatment.

$>\quad$ The study was limited to 5 sessions only and there was no follow up after that.
$>$ External factors affecting the progression cannot be calculated.

$>$ The study can be performed with a large sample size.

$>$ Long term follow up studies can be done to see the long term effects.

\section{REFFRENCES}

[1] Pamela K. Levangie, PT, DSc, FAPTA, Cynthia C. Norkin, PT, EdD, 2011, Joint Structure and Function Fifth Edition, Chapter no. 6 pg. 213

[2] Pamela K. Levangie, PT, DSc, FAPTA, Cynthia C. Norkin, PT, EdD, 2001 Joint Structure and Function Third Edition Pamela D. Ritzline, PT, EdD Chapter no. 6 pg. 188

[3] Mieszko Wieckiewicz, Klaus Boening, Piotr Wiland, Yuh-Yuan Shiau, Anna Paradowska-Stolarz Published on Dec 7, 2015 The Journal of Headache and Pain

[4] Marega S Medlicott, Susan R Harris, Published: 1 July 2006, Physical Therapy, Volume 86, Issue 7, 1 July 2006, Pages 995-973

[5] Leon Chaitow Muscle Energy Techniques Second Edition pg. 1

[6] Royder, 1981 Anderson 2004 "The Effect of Muscle Energy Technique on Temporomandibular Joint Dysfunction: A Randomized Clinical Trial" Volume 4 (1): 71-77, 2011

[7] Purusotham Chippala associate Professor Nitte Institute of Physiotherapy Nitte University, Derelakatte Mangaluru, and Karnataka, Essentials of Electrotherapy pg. 341

[8] Mieszko Wieckiewicz, Klaus Boening, Piotr Wiland, Yuh-Yuan Shiau, Anna Paradowska-Stolarz "Reported concepts for treatment modalites and pain management of temporomandibular disorder" The Journal of Headache and Pain, Published on Dec 7, 2015 